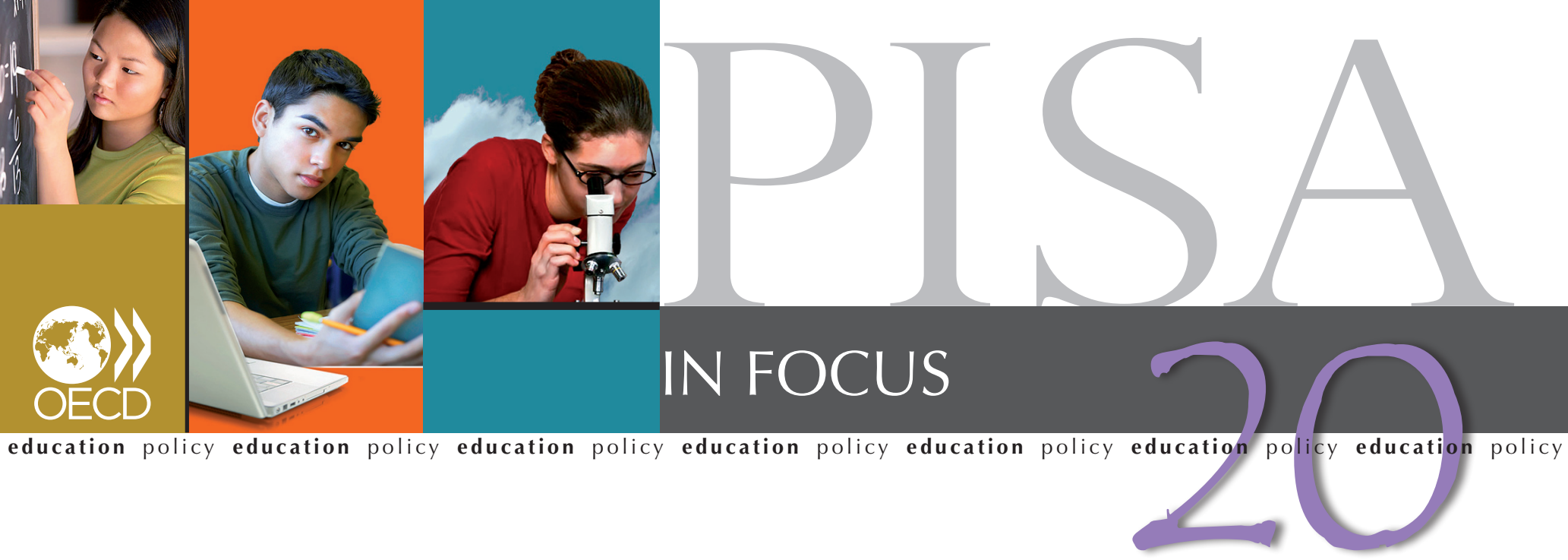

\title{
Are school vouchers associated with equity in education?
}

- Privately managed schools tend to attract more advantaged student populations; but the difference between the socio-economic profiles of public and private schools is narrowed when privately managed schools receive higher levels of public funding.

- The difference between the socio-economic profiles of publicly and privately managed schools tends to be twice as large in school systems that use universal vouchers as in systems that use targeted vouchers.

In recent years, an increasing number of education systems in OECD and partner countries have welcomed the involvement of private entities, including parents, non-governmental organisations and commercial enterprises, in funding and managing schools. The intention has been to offer greater choice to parents and students, and spur creativity and innovation within schools. Others have argued that this can inadvertently create a two-tier education system based on students' socio-economic backgrounds. If students are sorted into publicly or privately managed schools according to their family's wealth, educational opportunities and outcomes become unequal, undermining social cohesion.

Socio-economic advantage seems intrinsic to privately managed schools...
PISA data show that socio-economically advantaged parents tend to send their children to privately managed schools

more than disadvantaged parents do. They may do so because they believe that these schools offer a better education, an environment more conducive to learning, and additional resources; and advantaged parents tend to be more informed about or aware of the differences in quality among schools. Results from PISA show that, in most countries, privately managed schools tend to have more autonomy, better resources, and perform better on the PISA reading scale than publicly managed schools. But PISA also finds that, in all countries, privately managed schools seem to attract advantaged students largely because their student bodies are advantaged. Once socio-economic advantage has been taken into account, the performance of public and private schools tends to be very similar. 


\section{... but some countries have a narrower socio-economic gap between publicly and privately managed schools.}

In most PISA-participating countries and economies, the average socio-economic background of students who attend privately managed schools is more advantaged than that of students who attend public schools. In Canada, Chile, Greece, Mexico, New Zealand, Poland, Slovenia, Spain, the United Kingdom, the United States, the partner countries Albania, Argentina, Brazil, Colombia, Jordan, Kazakhstan, Kyrgyzstan, Panama, Peru, Tunisia, Uruguay and the partner economy Dubai (UAE), the difference between the socio-economic backgrounds of these two groups of students is very large. In contrast, in Luxembourg and the partner economy Chinese Taipei, the socio-economic background of students who attend publicly managed schools tends to be more advantaged than that of students who attend privately managed schools. Meanwhile, in Estonia, Finland, Israel, Korea, the Netherlands, the Slovak Republic, the partner country Indonesia and the partner economies Hong Kong-China and Shanghai-China, there is no difference between the socio-economic backgrounds of students who attend publicly managed schools and those who attend privately managed schools.

Difference between the socio-economic profiles of publicly and privately managed schools

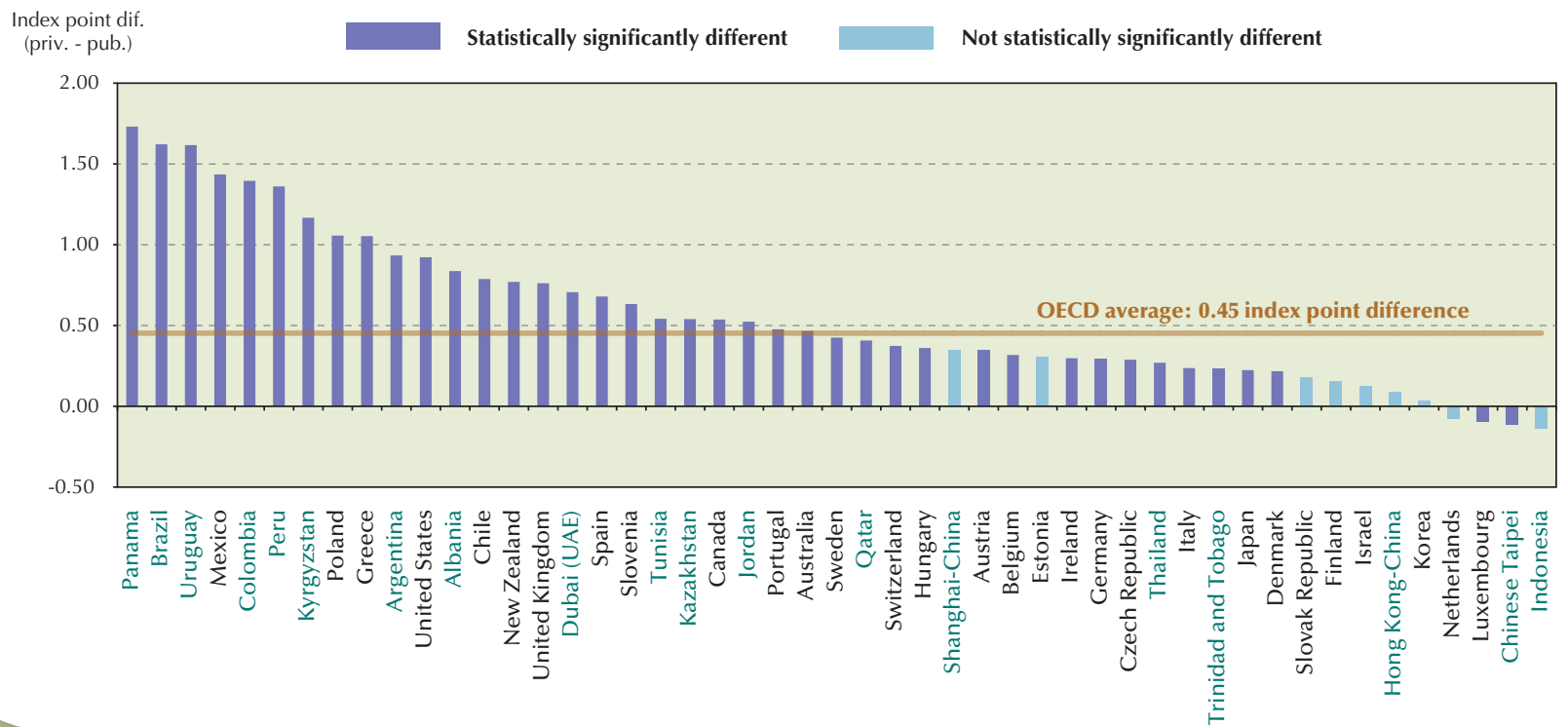

Students' socio-economic backgrounds are measured by the PISA index of economic, social and cultural status.

Countries are ranked in descending order of the index-point difference between privately managed and publicly managed schools. Source: OECD, PISA 2009 Database.

Public funding is key...

Why, then, is this difference more pronounced in some countries than in others? PISA results suggest that the level of public funding to privately managed schools may play a role. In Finland, the Netherlands, the Slovak Republic, Sweden and the partner economy Hong Kong-China, principals in privately managed schools reported that over $90 \%$ of school funding comes from the government; and in Belgium, Germany, Hungary, Ireland, Luxembourg and Slovenia between $80 \%$ and $90 \%$ of funding for privately managed school does. In contrast, in Greece, Mexico, the United Kingdom, the United States, the partner countries Albania, Jordan, Kyrgyzstan, Qatar, Tunisia, Uruguay, and the partner economy Dubai (UAE), $1 \%$ or less of funding for privately managed schools comes from the government; in New Zealand, the partner countries Brazil, Kazakhstan, Panama, Peru, and the partner economies Chinese Taipei and Shanghai-China, between $1 \%$ and $10 \%$ does. 

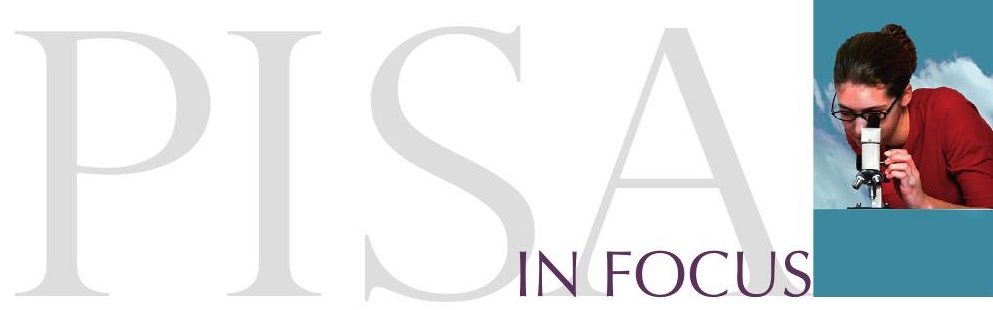

Countries that invest more public funds in privately managed schools tend to have less of a difference between the socio-economic profiles of publicly and privately managed schools

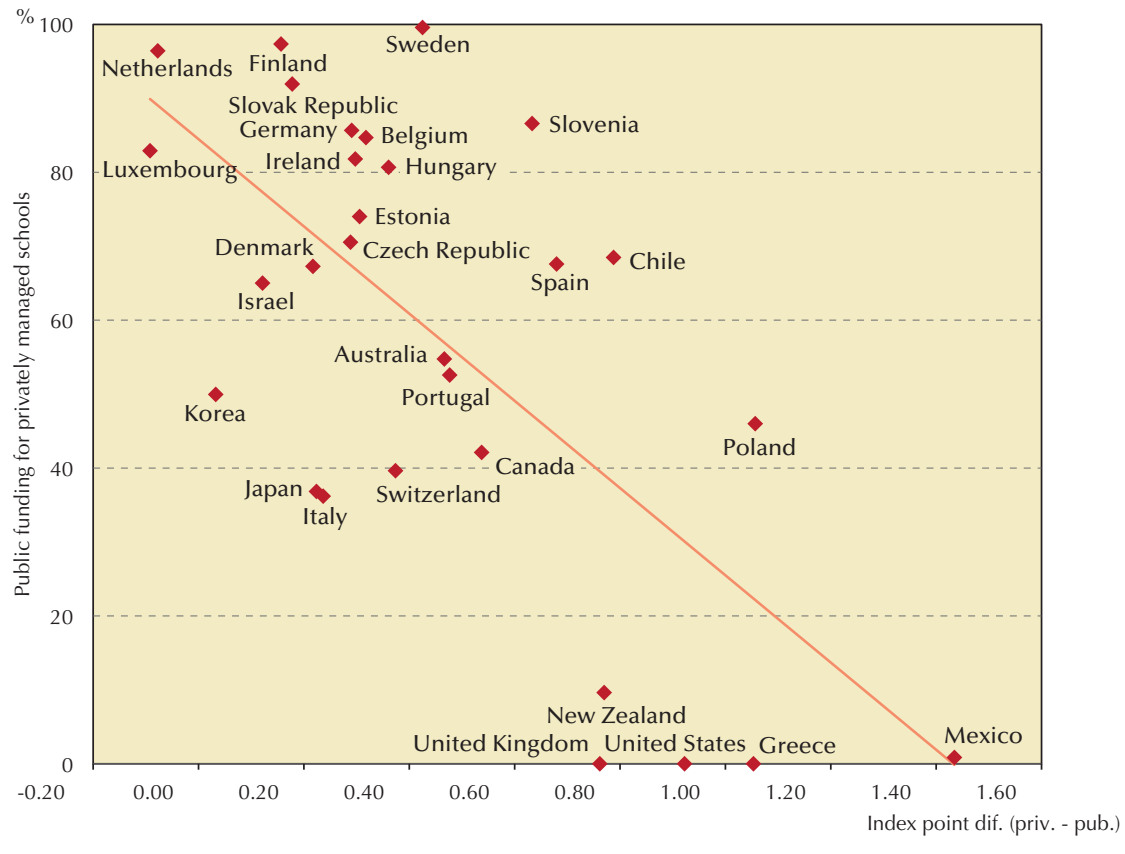

Difference between the socio-economic profile of privately and publicly managed schools

... and so is how that funding is provided.

There are many ways of providing public funding to privately managed schools. One way is through vouchers, which assist parents directly. Two types of voucher systems were considered in this analysis: universal voucher systems, in which vouchers are available to all students, and targeted voucher systems, in which vouchers are provided only to disadvantaged students. Vouchers that are available for all students can help to expand the choice of schools available to parents and promote competition among schools. School vouchers that target only disadvantaged students can help improve equity in access to schools. An analysis of PISA data shows that, when comparing systems with similar levels of public funding for privately managed schools, the difference between the socio-economic profiles of publicly managed schools and privately managed schools is twice as large in education systems that use universal vouchers as in systems that use targeted vouchers.
In those countries where privately managed schools receive higher proportions of public funding, there is less of a difference between the socio-economic profiles of publicly and privately managed schools. Across OECD countries, $45 \%$ of the variation in this difference can be accounted for by the level of public funding to privately managed schools; across all participating countries, $35 \%$ of the variation in this difference can be accounted for in this way.

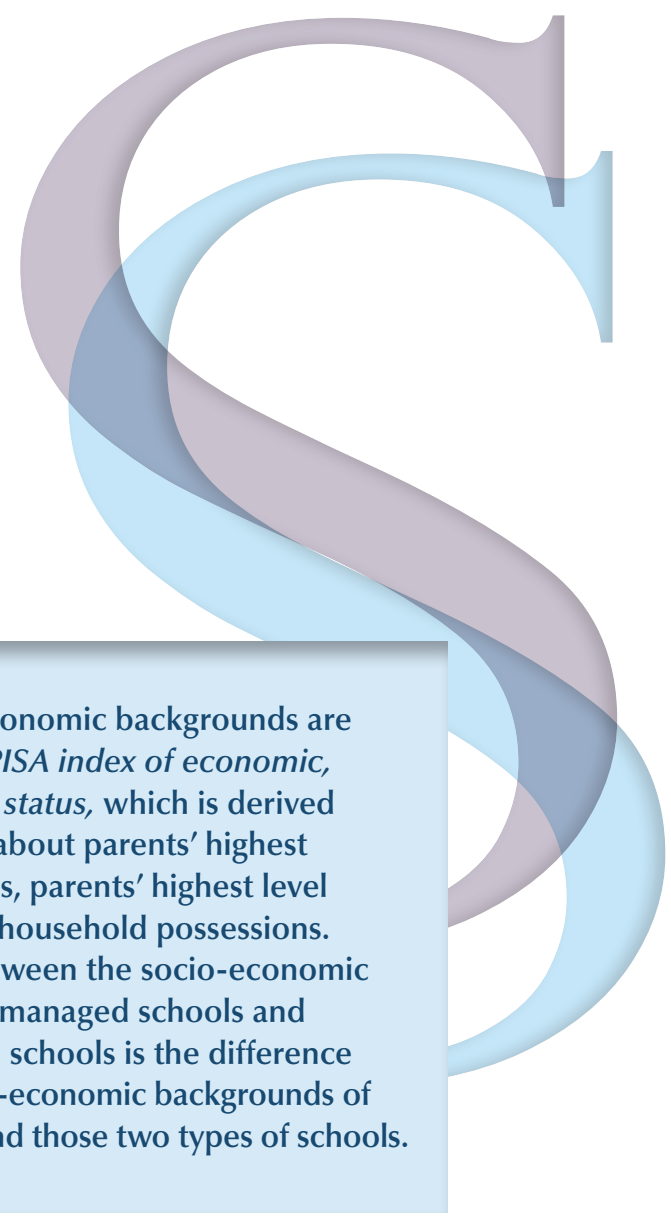


But the PISA findings also show that providing more public funding to privately managed schools will not necessarily eliminate that difference. In some countries, the difference is mainly explained by the fact that parents must pay more to send their children to privately managed schools; but in other countries, different school characteristics unrelated to funding, such as a school's admittance criteria, academic performance, policies, practices and learning environment, are also partly related to differences between schools' socio-economic profiles.
Crucially, PISA results show that those countries that have small differences between the socio-economic profiles of publicly and privately managed schools also tend to achieve better overall performance. This means that policy makers - and ultimately parents and students - do not have to choose between equity and strong performance in their school systems: the two are not mutually exclusive.
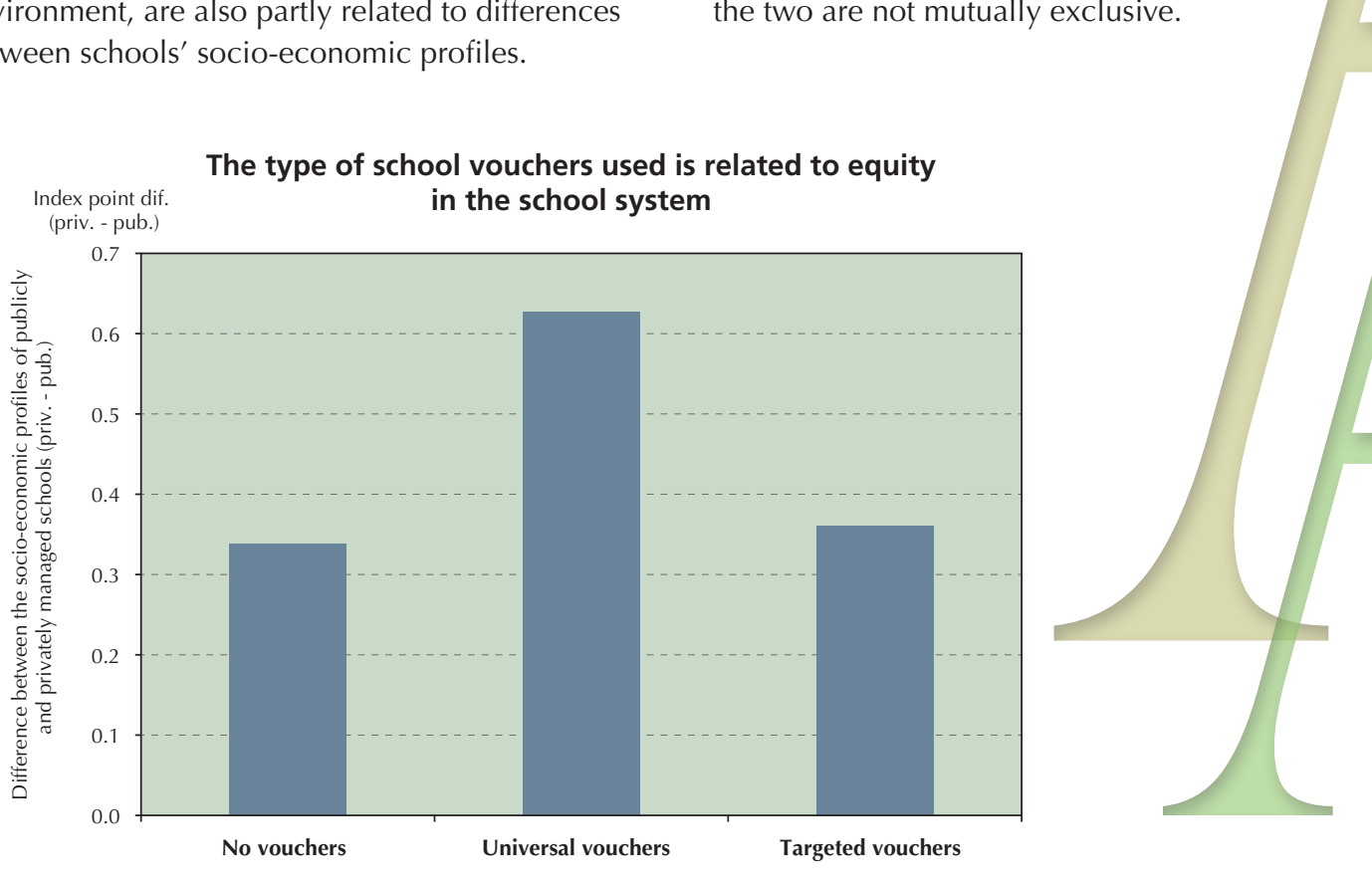

Source: OECD, PISA 2009 Database.

The bottom line: Countries that provide higher levels of public funding to privately managed schools are better able to guarantee that, irrespective of their socio-economic background, students can attend privately managed schools. When public funding is allocated through school vouchers, a targeted approach ensures greater equity than a universal approach.

\section{For more information}

Contact Miyako Ikeda (Miyako.Ikeda@oecd.org)

See Public and Private Schools: How management and funding relate to their socio-economic profile.

Visit

www.pisa.oecd.org www.oecd.org/pisa/infocus
Coming next month

Do today's 15 -year-olds feel environmentally responsible? 